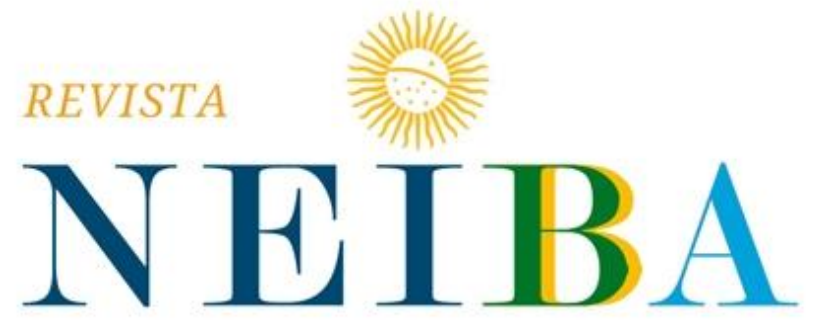

CADERNOS ARGENTINA-BRASIL
Volume 8, 2019, p. 01-14

DOI: 10.12957/neiba.2019.41867|e41867| ISSN: 2317-3459

\title{
O DESLOCADO INTERNO COMO CONCEITO: DA FORMAÇÃO DE UMA CATEGORIA ÀS IMPLICAÇÕES DO TERMO
}

THE INTERNAL DISPLACED AS A CONCEPT: FROM THE CREATION OF A CATEGORYTO ITS IMPLICATIONS

\section{Raquel Araújo de Jesus ${ }^{1}$}

${ }^{1}$ Universidade do Estado do Rio de Janeiro (UERJ), Rio de Janeiro, RJ, Brasil. E-mail: araujojraquel@gmail.com ORCID: https://orcid.org/0000-0001-6839-6177

Recebido em: 09 abr. 2019 | Aceito em: 18 dez. 2019. 


\section{RESUMO}

Dentre cerca de 68 milhões de pessoas no mundo que foram forçadas a abandonar suas asas e meios de sustento em busca de proteção, em torno de 40 milhões foram internamente deslocadas dentro dos seus países de origem (ACNUR, 2019). Estes indivíduos que não atravessaram uma fronteira reconhecida internacionalmente são categorizados como deslocados internos e, devido a sua condição supostamente ontológica, são frequentemente esquecidos e marginalizados nos âmbitos político e epistemológico das Relações Internacionais. Desta forma, o presente artigo tem como objetivo analisar tanto a criação do conceito de deslocado interno, no seio Nações Unidas (ONU), quanto a maneira pela qual esse processo de categorização, e rotulação, se insere em um escopo global e local de proteção e assistência. Como base empírica, são utilizados documentos oficiais e demais produções científicas sobre a temática, bem como o caso do deslocamento interno forçado de pessoas na Colômbia.

Palavras-chave: Deslocados Internos; Conceitualização; Colômbia; Fumigação

\section{ABSTRACT}

Among the 68 million people in the world who were forced to abandon their homes and livelihoods for protection, around 40 million were internally displaced within their countries of origin (UNHCR, 2019). These individuals who have not crossed an internationally recognized border are categorized as internally displaced and, because of their supposedly ontological condition, are often forgotten and marginalized in the political and epistemological realms of International Relations. Thus, this article aims to analyze both the creation of the concept of internally displaced person, within the United Nations (UN), and the way in which this process of categorization, and labeling, fits into a global and local scope of protection and assistance. As an empirical basis, official documents and other scientific papers on the subject are used, as well as the case of forced internal displacement of people in Colombia.

Keywords: Internally Displaced; Conceptualization; Colombia; Fumigation. 
INTRODUÇÃO

Tanto nos meios midiáticos quanto acadêmicos, atualmente observamos o crescimento de notícias e pesquisas científicas que têm por objetivo não apenas dar uma maior visibilidade aos múltiplos fenômenos de migrações forçadas, mas também compreender a atual conjuntura de desenraizamento e propor políticas públicas que sejam efetivas para o acolhimento e proteção das populações/indivíduos migrantes. Contudo, percebe-se que esta visibilidade se encontra, na maior parte dos casos, tangenciada aos fluxos migratórios transnacionais, sejam eles de migrantes econômicos, ambientais e/ou refugiados. Neste sentido, percebe-se uma marginalização acadêmica e política, nas Relações Internacionais, daqueles que qualitativamente encontram-se na mesma condição dos refugiados, mas que, por motivos variados, não atravessaram uma fronteira reconhecida internacionalmente.

Enquanto a criação do conceito de refugiado, e do seu arcabouço jurídico internacional de proteção, ocorreu no pós-Segunda Guerra Mundial através da Convenção de Genebra de 1951, a formação do conceito de deslocado interno data do pós-Guerra Fria, quando, em 1998, foi elaborado, no seio das Nações Unidas, o documento intitulado "Princípios Orientadores Relativos aos Deslocados Internos". Ao analisar tais documentos, percebe-se que ambas as categorias possuem características semelhantes. Entretanto, o que essencialmente irá distinguir uma categoria da outra é o fato de o refugiado ter atravessado uma fronteira internacional e, por este motivo, ser reconhecido pelos mecanismos internacionais de proteção. Uma vez que o deslocado interno permanece dentro do seu Estado de origem, a sua categorização não possui uma base normativa, mas apenas funcional (Oliveira, 2004). Na prática, o que acontece é que, embora o documento de 1998 apresente um conceito abrangente de deslocado interno, ele não possui força de lei, ou seja, ele não vincula juridicamente os Estados. Logo, fica a cargo do próprio Estado de origem, em caráter primário, proteger e assistir aqueles que estão em situação de deslocamento interno forçado, ainda que este Estado seja o maior violador dos seus direitos.

Desta forma, o presente artigo visa analisar o processo de formação do conceito de deslocado interno, no seio ONU, e a maneira pela qual sua categorização, e rotulação, 
se insere em um escopo global e local de proteção e assistência que, por sua vez, tem impactos significativos para o próprio indivíduo deslocado. O argumento central do texto é que, devido a sua condição supostamente ontológica, o deslocado interno é frequentemente esquecido e marginalizado nos âmbitos político e epistemológico das Relações Internacionais. Como base empírica para esta construção argumentativa, são utilizados documentos oficiais e demais produções científicas sobre a temática a luz do caso de deslocamento interno forçado de pessoas na Colômbia, país que, até os dias de hoje, possui o maior número de deslocados internos em nível mundial (ACNUR, 2019).

\section{A FORMAÇÃO INTERNACIONAL DO CONCEITO}

No final da década de 1980, com o aumento no número de guerras irregulares e dos conflitos armados internos oriundos de um contexto de Guerra Fria, diversas Organizações Não-governamentais (ONGs) e ativistas de direitos humanos começaram a indicar a necessidade de tratar a questão dos deslocamentos internos forçados de pessoas sob o "guarda-chuva" da ONU. Como consequência deste movimento e por recomendação da Comissão de Direitos Humanos da ONU $(\mathrm{CDH})$, o então Secretário das Nações Unidas, Boutros Boutros-Ghali, em 1992, nomeou o ex-diplomata sudanês, Francis M. Deng, para apresentar um relatório que abordasse os principais obstáculos enfrentados por estas populações ao redor do mundo. O objetivo final do trabalho era pensar em uma estratégia comum a todos os países e que pudesse proteger e assistir as pessoas internamente deslocadas.

Desta maneira, o relatório apresentado identificou diversas lacunas que precisavam ser preenchidas e sanadas. Uma destas lacunas era a inexistência de um organismo da ONU cujo mandato fosse especificamente direcionado para cobrir as necessidades dos deslocados internos. Diversas foram as opções levantadas para suprir esta deficiência. Dentre as opções estava a criação de uma nova agência ou então a atribuição deste papel a alguma agência já existente. No que tange à segunda opção, o relatório ressaltou que o ACNUR teria o mandato mais pertinente para necessidades dos deslocados internos (ONU 1993, p. 25); a agência, inclusive, já teria atuado em alguns casos anteriormente. Entretanto, foi decidido que, como o deslocamento interno forçado de pessoas lida com questões sensíveis aos Estados (soberania, fronteira, 
proteção, responsabilidade e intervenção) o mais recomendado seria criar um tipo de dispositivo capaz de mobilizar as diversas agências, órgãos e organizações, que fazem parte ou não do sistema ONU, para que haja uma atuação coordenada nos casos de assistência humanitária às populações vítimas dos deslocamentos.

Como consequência desta mobilização, em 1998, através do Escritório das Nações Unidas para a Coordenação de Assuntos Humanitários (OCHA), foram estabelecidos os "Princípios Orientadores Relativos aos Deslocados Internos". Estes princípios se baseiam no respeito ao Direito Internacional, em particular à Declaração Universal dos Direitos Humanos e ao Direito Internacional Humanitário. Este documento possui como finalidade identificar os direitos e as garantias relevantes para a proteção das pessoas contra o deslocamento forçado e a sua proteção e assistência durante o deslocamento, bem como o seu reassentamento e reintegração local. Para isto, veio à tona a necessidade de criar uma definição geral, ou seja, de um conceito único capaz de categorizar o que, segundo a ONU, é considerado um deslocado interno. Desta maneira, logo em sua introdução, o documento define que

os deslocados internos são pessoas, ou grupos de pessoas, forçadas ou obrigadas a fugir ou abandonar as suas casas ou seus locais de residência habituais, particularmente em consequência de, ou com vista a evitar, os efeitos dos conflitos armados, situações de violência generalizada, violações dos direitos humanos ou calamidades humanas ou naturais, e que não tenham atravessado uma fronteira internacionalmente reconhecida de um Estado. (Ohchr, 1998).

Em crítica, Eduardo Cançado Oliveira (2004) observa que uma das questões mais debatidas acerca da proteção dos deslocados internos é a adoção de uma definição capaz de englobar todas as situações de deslocamento interno forçado, sem que o indivíduo nesta situação tenha os seus direitos tolhidos. Assim, ainda que a definição empregada pelo documento seja abrangente, o autor ressalta que, na prática, tanto os Estados quanto os organismos internacionais adotam definições mais restritas. De fato, tanto o ACNUR quanto o Comitê Internacional da Cruz Vermelha (CICV) empregam definições de trabalho mais limitadas. Enquanto a Agência reconhece como deslocado interno apenas aquele que poderia ser categorizado como refugiado, caso atravessasse uma fronteira internacionalmente estabelecida, o Comitê delimita o conceito de 
deslocado interno àquele que foi forçado a se deslocar por consequência de um conflito armado.

Percebe-se, então, que a própria condição supostamente ontológica do deslocado interno faz com que a sua crise seja frequentemente esquecida e marginalizada. Conforme apontado por Emma Haddad (2008), enquanto o "problema" do refugiado só é colocado na agenda internacional para discussão e resolução quando é visto como uma ameaça à ordem e a estabilidade do sistema de Estados, aqueles que são obrigados a fugir pelos mesmos motivos, mas não têm êxito em cruzar fronteiras internacionais, por mais diversas que sejam as razões, são categorizados como deslocados internos e, consequentemente, perecem de proteção internacional. Nas palavras da autora,

em oposição ao refugiado, os deslocados internos permanecem como uma questão interna do seu Estado de origem seja por razões de soberania e de não intervenção ou devido à realista falta de interesse por responsabilidade humanitária (Haddad 2008, p.62).

De fato, os mecanismos até então desenvolvidos em nível internacional para proteger as populações internamente deslocadas ainda são insuficientes para dar respostas satisfatórias à tamanha crise humanitária que presenciamos hoje em países como a Colômbia, com cerca de 8 milhões de deslocados internos reconhecidos pelo governo (ACNUR, 2019).

Conforme ressaltado por Oliveira (2004), um dos grandes obstáculos para a proteção do deslocados internos é a inexistência de um corpo normativo internacional que seja de caráter vinculante e direcionado especificamente a estas pessoas. Ao contrário dos refugiados, os deslocados internos não possuem um estatuto jurídico internacional de proteção. Em contrapartida, o documento elaborado em 1998 propõe apenas uma definição funcional e não um estatuto jurídico internacional de proteção; o seu papel é descrever uma situação e possibilitar a atuação humanitária. Consequentemente, aqueles que são vítimas de deslocamento forçado e permanecem dentro do seu país de origem, muitas vezes, ficam desprovidos de proteção internacional e nacional, principalmente quando o próprio Estado é principal violador dos seus direitos. Neste sentindo, é importante observarmos que, de acordo com o documento elaborado, é de responsabilidade primária das autoridades nacionais 
garantir a proteção e a assistência aos deslocados que se encontram sob a sua área de jurisdição, bem como prevenir e impedir que aconteçam novos episódios de deslocamento.

Devido à ausência de um organismo internacional cujo mandato seja especificamente salvaguardar os direitos das populações internamente deslocadas, o ACNUR há muitos anos tem prestado assistência para estas pessoas. Recentemente, com a Reforma Humanitária das Nações Unidas (2005), foi atribuído a ele um papel de liderança, configurada em um droit de regarde, no que tange a coordenação da assistência humanitária aos deslocados internos in loco. A estratégia desenvolvida se dá por uma abordagem de nichos (cluster approach), que visa supervisionar as necessidades de proteção e abrigo dos deslocados internos, bem como coordenar e gerenciar os acampamentos direcionados a estas pessoas dentro dos países. Além disso, às demais organizações humanitárias, cabe o direito de oferecer o seu apoio e assistência sem que isto seja configurado como ingerência à soberania do Estado em questão. Para que isto ocorra, as autoridades competentes devem facilitar a atuação destes organismos em território nacional (Ohchr, 1998, Princípios 03, 05 e 25).

\section{A FORMAÇÃO LOCAL DO CONCEITO}

Conforme ressaltado anteriormente, e embora estes números sejam sempre contestados, a Colômbia atualmente possui cerca de 8 milhões de deslocados internos reconhecidos pelo governo; o que torna o país com o maior número de deslocados internos em nível mundial (ACNUR, 2019). As proveniências do deslocamento forçado no país são complexas e estão relacionadas com os conflitos políticos, sociais e econômicos do país (Ibáñez; Querubín, 2004). De fato, a Colômbia é marcada por disputas e violências políticas que, ao longo de sua história, levaram a massacres, assassinatos, desaparecimentos e deslocamentos forçados de populações.

Contudo, em um contexto de Guerra Fria, a emergência de grupos armados insurgentes, contrainsurgentes e narcotraficantes, deram novos contornos ao cenário de violência no país (HYLTON, 2010). Ao longo dos anos, a violência foi acompanhada pela forte presença dos militares nos assuntos de manutenção da ordem e da segurança pública (Atehortúa, 2001; Palou, 1993). Como resultado, houve o 
agravamento do conflito armado interno em regiões controladas pelos grupos a margem da lei (Hylton, 2010; Pécaut, 2010). Neste sentido, cabe ressaltar que estes grupos atuam em determinados departamentos e municípios da Colômbia não de forma contingente, mas sim devido a algum atrativo geoestratégico e econômico na região (Hylton, 2010). De maneira similar, conforme apontado por Ana M. Ibáñez (2008), os ataques à população civil não é um subproduto da guerra e sim uma estratégia deliberada de guerra, visto que, ao despovoar uma região forçando o deslocamento, os grupos armados expandem a sua hegemonia sobre o território e se apropriam de bens públicos e privados.

Assim, em 1995, o deslocamento interno forçado de pessoas no país tomou proporções tão graves que a Igreja Católica, através da Conferência Episcopal sobre deslocamento interno forçado de pessoas, apresentou um documento que mapeava e contabilizava os eventos ocorridos até aquela data e que chegaram ao conhecimento da Instituição (Pécaut, 2010). Segundo Daniel Pécaut (2010), naquela data, o documento estimava um número de 500 mil deslocados internos no país. Como efeito, além de ter chamado a atenção da comunidade internacional e de diversas organizações de direitos humanos, a iniciativa da Igreja fez com que, em 1997, o governo colombiano adotasse a primeira legislação nacional capaz de reconhecer não apenas a existência do deslocamento forçado de pessoas no país, mas também a sua responsabilidade para com os deslocados.

Desta forma, a Lei 387 de 1997 representa o marco jurídico de proteção dos direitos das populações internamente deslocada na Colômbia. Desta lei, posteriormente, desprendem-se uma série de decretos e diretivas presidenciais que possuem como núcleo a proteção das pessoas internamente deslocadas (Dario, 2009). A lei estabelece, por exemplo, a formação de uma rede de apoio e assistência aos deslocados internos em nível nacional e local, contando com a participação de entidades públicas, privadas e comunitárias, além de medidas de prevenção e de um sistema de Registro Único da População Deslocada (RUPD). Contudo, desde 2011, no marco da Lei de Vítimas e de Restituição de Terras (Lei 1448), o RUPD foi substituído pelo Registro Único de Vítimas (RUV). Além disso, no entendimento da nova lei, são 
considerados como vítimas, bem como deslocados internos, apenas aqueles que tenham sofrido danos, a partir da data de $1^{\circ}$ de janeiro de 1985, por consequências do conflito armado interno. Desta forma, a Lei 1448 apresenta uma definição bem mais restrita de deslocado interno do que a Lei $387^{1}$ apresentava. Contudo, embora críticas possam e devam ser feitas quanto a sua aplicação e efetividade, decorre que, ainda hoje, a legislação colombiana é vista como uma das mais completas do mundo.

Portanto, percebe-se que a definição de deslocado interno adotada atualmente pela Colômbia se assemelha àquela utilizada tanto pela CICV quanto pelo ACNUR. Para as três instituições, o deslocado interno é aquele que está em uma refugee-like situation (situação análoga ao refúgio) e que, caso cruzasse uma fronteira internacional, seria reconhecido como um refugiado. A questão é que, no caso ilustrado, a dicotomização do conceito de deslocado interno, da mesma forma com que cria um escopo legal de proteção e assistência a uma determinada parcela da população deslocada, segrega e marginaliza a outra parcela que, no limite, acaba sendo sobrevitimizada (Jesus, 2017).

O caso colombiano é emblemático para entendermos essa dinâmica de inclusão e exclusão, ou seja, de estabelecimento de uma fronteira entre quem merece proteção e assistência daqueles não merecem. Através do arcabouço jurídico desenvolvido para os deslocados internos em nível nacional, não são reconhecidos, por exemplo, aqueles que foram forçados a abandonar suas casas e meios de sustento devido aos efeitos nocivos das fumigações das plantações de coca na Colômbia (Ceballos, 2003). A fumigação consiste na aspersão aérea de produtos químicos, tal como o glifosato, nas plantações de cultivos ilícitos no país e foi amplamente empregada durante a década de 2000 via Plano Colômbia². Segundo Marcela Ceballos (2003), esta estratégia se tornou bastante

\footnotetext{
1 Segundo o artigo 1ㅇ da Lei 387, são reconhecidos como deslocados internos aqueles "que foram forçados a migrar dentro do território nacional abandonando seu local de residência ou atividades econômicas habituais, porque sua vida, sua integridade física, sua segurança ou liberdade pessoais foram solapadas ou se encontram diretamente ameaçadas, devido a qualquer das seguintes situações: Conflito armado interno, distúrbios e tensões interiores, violência generalizada, violações massivas de Direitos Humanos, infrações ao Direito Internacional Humanitário ou outras circunstâncias emanadas das situações anteriores que possam alterar ou que alterem drasticamente a ordem pública" (Lei 387/97).

2 Firmado entre os governos de Andrés Pastrana e Bill Clinton, o Plano Colômbia foi um pacote de ajudas estadunidense nos âmbitos político, militar e financeiro para o combate às drogas no país. Em um primeiro momento, seu objetivo principal era a redução do cultivo, processamento e distribuição de drogas ilícitas na Colômbia em 50\% dentro de seis anos (Santos, 2006; Rodrigues, 2012).
} 
controversa ao longo dos anos, pois demonstrava ser tanto contraproducente - visto que não resultou em uma diminuição significante nas plantações de coca e papoula no país, mas sim a sua dispersão territorial (Rodrigues, 2012; Stein, 2007) - quanto causava prejuízos sociais, econômicos e ambientais; afetando o direito à alimentação, ao colocar em perigo a segurança alimentar dos habitantes locais, e afetando o direito à saúde, à educação e de gozar de um meio ambiente saudável.

Como o glifosato é um herbicida não seletivo, a sua utilização na fumigação dos cultivos ilícitos afeta diretamente a vida daqueles que vivem em seus arredores. Assim, com a finalidade de combater o narcotráfico no país e na região, a aspersão aérea de produtos químicos destruía também os cultivos lícitos, seja por aplicação direta ou por contaminação do solo e da rede fluvial. Tendo em vista que uma parcela significante da população colombiana vive da agricultura de subsistência, a fumigação acarreta a fome e a exacerbação da pobreza no meio rural, além de provocar danos à saúde da população; são inúmeros os relatos e denúncias que associam problemas respiratórios e cancerígenos ${ }^{3}$ à utilização do glifosato (Jesus, 2017).

Segundo o relatório da Unidad para la Atención y Reparación Integral a las Víctimas (UARIV, 2013), em meados da década de 2000, Nariño se tornou o quinto principal departamento de expulsão de populações na Colômbia devido a expansão dos cultivos ilícitos para a região, indicando a relação entre fumigação e deslocamento interno forçado de pessoas na Colômbia. Como consequência, temos uma categoria de deslocamento forçado que é tanto vítima das consequências diretas de uma política pública de combate ao narcotráfico quanto do desamparo do Estado que, sendo responsável por garantir os seus direitos, não os reconhece como deslocados internos, o que implica na sobre-vitimização destes indivíduos.

Portanto, cabe refletir sobre algumas questões que não podem passar despercebidas: o que queremos dizer com o termo "deslocado interno"? Quem faz a distinção? Quem define quem é e quem não é um deslocado interno? É preciso ter em

\footnotetext{
${ }^{3}$ Em 2015, a Organização Mundial da Saúde (OMS) divulgou um relatório indicando a potencialidade cancerígena do glifosato e, devido uma decisão da Corte Constitucional colombiana, as fumigações haviam sido suspensas. Contudo, desde a eleição de Donald Trump, os Estados Unidos vinham pressionando o governo colombiano para retomadas desta estratégia (Público, 2017). Em junho de 2019, o atual presidente colombiano, Iván Duque, declarou a retomada das atividades (El País, 2019).
} 
mente que existe um jogo de interesses ao falarmos sobre o tema, ou seja, o discurso produzido aparece sempre associado a interesses e compromissos políticos e, assim, como todo conhecimento, ele não é neutro. Michel Foucault (2003) ao analisar a relação entre poder e produção de verdades, de saberes e de conhecimento, indica que nenhum saber é neutro e que toda a produção de saber é politicamente intencionada. Assim, podemos perceber que a criação de um conceito como o de "deslocado interno", da mesma forma com que concede um tratamento especial àqueles em situação de vulnerabilidade, atua como uma espécie de rótulo, de categorização, que, ao mesmo tempo, é excludente.

Como mencionado anteriormente, tanto os Estados quanto os organismos internacionais apresentam definições restritas acerca de quem são essas pessoas, sobre quem merece ou não gozar de assistência e proteção. É um processo de descrição e de valoração e, desta forma, "[...] descrever não é simplesmente dar um nome, mas categorizar e esta categorização inevitavelmente toma lugar a partir de certa perspectiva, de acordo com determinados interesses, objetivos ou critérios" (Haddad 2008 , p. 25). A criação de um conceito controla quem o recebe em termos tanto qualitativos, quem são, quanto quantitativos, quantos são. Se, de um lado temos o Estado que tenta limitar ao máximo essa definição para diminuir o escopo, ou seja, diminuir o número daqueles que são contemplados por esta definição - seja para aliviar o fardo econômico que podem acarretar ou para eximir-se da culpa e da responsabilidade por tê-los produzidos - por outro lado, temos o indivíduo sedento de amparo e proteção que necessita da ampliação deste escopo.

\section{CONCLUSÃO}

Este artigo mostra como o processo de criação do conceito de deslocado interno, em nível internacional e local, na forma com que foi feita, apresenta limitações e implicações que, por sua vez, corroboram com a vulneração das populações internamente deslocadas. Criar um conceito é, necessariamente, categorizar e o processo de categorização é também um processo de valoração e, desta forma, politicamente intencionado e teoricamente definido. Portanto, ainda que a 
conceituação gere uma linguagem comum, que no caso do deslocado interno proporciona, em certa medida, ações "efetivas" para proteção e assistência destes indivíduos, não podemos esquecer que através deste processo, entre o concreto e o abstrato, existem trade-offs que, no caso analisado, se manifestam através da marginalização, desproteção, não assistência e, no limite, sobre-vitimização de parcelas destas populações.

\section{REFERÊNCIAS BIBLIOGRÁFICAS}

ACNUR (2019). Global Trends 2018. Disponível em: <https://www.unhcr.org/statistics/unhcrstats/5d08d7ee7/unhcr-globaltrends2018.html>. Acesso em: 29 jul. 2019.

Atehortúa Cruz, A. L. (2001). Las fuerzas militares en Colombia: de sus orígenes al Frente Nacional. In: Revista Historia y Espacio, n.17.

Ceballos, M. (2003). Plan Colombia: contraproductos y crisis humanitaria. fumigaciones y desplazamiento en la frontera con Ecuador. CODHES, Bogotá, outubro, 2003.

CICV (1949). (I) Convenção de Genebra. Disponível em: <https://ihldatabases.icrc.org/applic/ihl/ihl.nsf/INTRO/365?OpenDocument>. Acesso em: 02 ago. 2019.

(1977). (II) Protocolo Adicional às Convenções de Genebra. Disponível em: <https://ihl- databases.icrc.org/applic/ihl/ihl.nsf/INTRO/475?OpenDocument>. Acesso em: 02 ago. 2019.

Colombia. Ley 387 de 18 de julio de 1997. Reglamentada Parcialmente por los Decretos Nacionales 951, 2562 y 2569 de 2001 por la cual se adoptan medidas para la prevención del desplazamiento forzado; la atención, protección, consolidación y esta estabilización socioeconómica de los desplazados internos por la violencia en la República de Colombia.

Ley 1448 de 10 de junio de 2011. Reglamentada por el Decreto Nacional 4800 de 2011 y por el Decreto Nacional 3011 de 2013 por la cual se dictan medidas de atención, asistencia y reparación integral a las víctimas del conflicto armado interno y se dictan otras disposiciones.

Comission On Human Rights (1993). Comprehensive study prepared by Mr. Francis M. Deng, representative of the Secretary-General on the human rights issues related to internally displaced persons. E/CN.4/1993/35. 
Dario, D. M. (2009). As populações internamente deslocadas pelo conflito colombiano durante o governo Uribe: uma reflexão sobre os usos da segurança humana na era da 'Guerra ao Terror'. 159 f. Dissertação (Mestrado em Relações Internacionais) Pontifícia Universidade Católica do Rio de Janeiro, Rio de Janeiro.

El País (2019). Colombia recupera las polémicas fumigaciones con glifosato contra los cultivos de coca. Bogotá, 30/06/2019. Disponível em: <https://elpais.com/internacional/2019/06/28/colombia/1561756122 650334.html>. Acesso em: 02 ago. 2019.

Foucault, M. (2003). Poder e saber. In: Ditos e Escritos Vol. IV. Organização e seleção de textos Manoel Barros da Motta; Tradução Vera Ribeiro. Rio de Janeiro: Forense Universitária.

Haddad, E. (2008). The refugee in international society: between sovereigns. Cambridge: Cambridge University Press.

(2004). Who is (not) a refugee? Italy: European University Institute.

Hylton, F. (2010). A revolução colombiana. São Paulo: Unesp.

Ibáñez, A. M. L.; QUERUBíN, P. (2004). Acceso a tierras y desplazamiento forzado en Colombia. Bogotá: Universidad de los Andes. Disponível em: <http://www.acnur.org/t3/uploads/media/COI_2497.pdf>. Acesso em: 09 abr. 2019.

Ibáñez, A. M. L. (2008). El desplazamiento forzoso en Colombia: un camino sin retorno hacia la pobreza? Bogotá: Universidad de los Andes, Facultad de Economia.

Jubilut, L. L. (2008). A reforma humanitária na ONU e a necessidade de uma abordagem baseada em direitos para a assistência humanitária internacional. In: Revista Carta Internacional, 3(1).

Ohchr (1998). Princípios orientadores relativos aos Deslocados Internos. Disponível em: $<$ http://www.ohchr.org/Documents/Issues/IDPersons/GPPortuguese.pdf>. Acesso em: 09 abr. 2019.

Oliveira, E. C. (2004). A proteção jurídica internacional dos deslocados internos. In: Revista do Instituto Brasileiro de Direitos Humanos, 5(5).

ONU (1948). Declaração Universal dos Direitos Humanos. Disponível em: <http://unesdoc.unesco.org/images/0013/001394/139423por.pdf>. Acessoem: 09 abr. 2019.

Palou, J. C. (1993). Las fuerzas armadas y la transición constitucional en Colombia. FASOC, vol. VIII(4). 
Pécaut, D. (2010). As FARC: Uma guerrilha sem fins? São Paulo: Paz e Terra.

Público (2017). EEUU presiona a Colombia para que reanude la fumigación aérea con glifosato contra los cultivos de coca. Bogotá, 27/06/2017. Disponível em: $<$ https://www.publico.es/internacional/glifosato-eeuu-presiona-colombia-reanudefumigacion-aerea-glifosato-cultivos-coca.html>. Acesso em: 02 ago. 2019.

Rodrigues, T. M. S (2012). Narcotráfico e militarização nas Américas: Vício de Guerra. In: Contexto Internacional, Rio de Janeiro, 34(1), janeiro-junho, pp. 9-41.

Santos, M. (2006). O Plano Colômbia e o primeiro mandato de Uribe (2002-2006). In: Cena Internacional, 8(2).

Stein, M. (2007). Criticism of fumigation grows in Colombia as cocaine trade is undiminished. World Politcs Review. Disponível em: $<$ https://www.worldpoliticsreview.com/articles/929/criticism-of-fumigation-grows-incolombia-as-cocaine-trade-is-undiminished>. Acesso em: 02 ago. 2019.

UARIV (2013). Informe nacional de desplazamiento forzado en Colombia (1985-2012). Bogotá, Colômbia, jun. 